\section{Agricultural impact of Chernobyl: a warning}

SIR-Since the evening of 30 April 1986, when a series of thunderstorms brought down heavy fallout from Chernobyl along the northern flank of the Alps, we have conducted high-resolution $\gamma$ spectroscopy measurements on rain water, on a high-efficiency particulate air (HEPA) filter and on various agricultural products from the region around Konstanz (West Germany). Our results on the purely physical aspects of the fallout are comparable to those already published ${ }^{1,2}$. Specifically, from the activity ratio ${ }^{103} \mathrm{Ru} /{ }^{106} \mathrm{Ru}$ $=4.5(5)$ and the published values of fission yields, we estimate the age of the Chernobyl core to be $2.0(5)$ yr. In addition, from a detailed analysis of activities, we infer relative release fractions in six of seven volatility classes and conclude that Chernobyl released core activity in the same proportions as the extensively documented 'reference accident' $(\mathrm{PWR} 2)^{3.4}$. This putative accident involved core melting and complete loss of containment of a 1,100-MW (electric) light-water reactor. Our observations are therefore consistent with a core melt at Chernobyl.

In the course of monitoring agricultural products and ground activity around Konstanz, we have noted three aspects of Chernobyl fallout that may have considerable practical importance for agricultural management, both in strongly contaminated regions close to Chernobyl and in many parts of Western Europe.

(1) Fallout from Chernobyl shows extreme geographical variability over short distances, depending on rainfall patterns prevailing when the cloud passed. For example, within the West German state of Baden-Württemberg, a region of $\sim 175 \times$

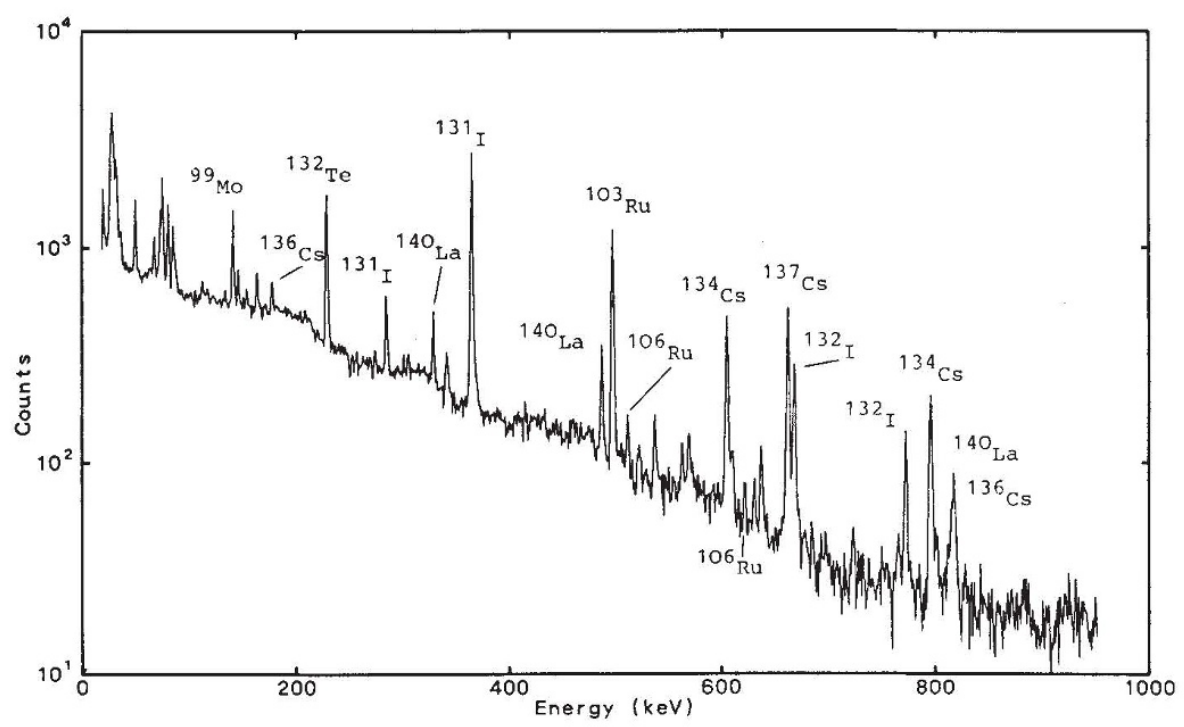

Fig. 1. Gamma-ray spectrum of grass recorded on 10 May 1986 showing dominant isotopes present in adhering particulates.
$225 \mathrm{~km}$, gross $\beta$ activity at ground level, determined uniformly, varied by up to 30 fold (data from the Landesregierung Baden-Württemberg).

(2) Fallout aerosols brought down by rainfall show a high resistance to weathering and drying. In experiments we found that grass dried at $130^{\circ} \mathrm{C}$ for $24 \mathrm{~h}$, followed by vigorous shaking, lost less than 10 per cent of the adhering ${ }^{131} \mathrm{I},{ }^{132} \mathrm{I} /{ }^{132} \mathrm{Te}$, ${ }^{134} \mathrm{Cs},{ }^{136} \mathrm{Cs},{ }^{137} \mathrm{Cs},{ }^{140} \mathrm{Ba} /{ }^{140} \mathrm{La},{ }^{99} \mathrm{Mo}$, and ${ }^{10.3} \mathrm{Ru}$ (Fig. 1).

(3) Cutting, drying and storing grass for winter cattle feed will therefore lead to radioactive accumulations in silos and barns. Near Konstanz, where ground activity includes $\sim 10^{4} \mathrm{~Bq} \mathrm{~m}{ }^{-2}$ of ${ }^{137} \mathrm{Cs}$ (halflife $\simeq 30 \mathrm{yr}$ ), direct measurement and calculations lead us to expect $\sim 0.2-5 \mathrm{mCi}$ of ${ }^{137} \mathrm{Cs}$ in typical small-farm storage facilities. Further east much larger ground activity has been reported and correspondingly larger accumulations are likely.

According to radiation protection laws in most countries, transport and storage of such quantities requires user licences that are normally reserved for a few wellequipped scientific and technological institutions. From a health perspective, the expected accumulations will contaminate barns, lead to significant exposure of farm workers and may pose special threats to children.

The problem of hay accumulation and storage may be all the more acute in view of the recent discovery ${ }^{1}$ that fallout aerosols contain $1-2-\mu \mathrm{m}$ 'hot' $\beta$-emitting particles with single-isotope source strengths of $1,000-10,000 \mathrm{~Bq}$. If these are widespread constituents of Chernobyl fallout, they can be expected to be trapped 'permanently' in the lungs of individuals exposed to contaminated hay.

To our knowledge the biological effects of such hot $\beta$-emitting particles are not

\section{University of Konstanz, \\ D-7750 Konstanz, FRG}

Fakultät für Physik,

*Permanent addresses: Clark University, Worcester, Massachusetts 01610, USA (C.H.); University of Connecticut, Storrs, Connecticut 06268, USA (J.I.B.)

1. Devell, L. et al. Nature 321, 192-193 (1986)

2. Fry, F.A., Clarke, R.H., \& O'Riordan M.C. Nature 321, 193-195 (1986)

3. US Nuclear Regulatory Commission Reactor Safety Study (Wash 1400, NUREG 75/014) (Washington 1975). 4. Lewis, H.W. et al. Rev. mod. Phys. 47, Suppl. 1, SI (1975).

\section{First assessment of Chernobyl radioactive plume over Paris}

SIR-Measurements of the gammaradioactivity of the surface air in Paris after the Chernobyl accident have shown that the maximum concentrations of ${ }^{137} \mathrm{Cs}$ over a period of three days were $4(0)$ times greater than during the worldwide fallout of 1963. Preliminary estimates of ground deposition of ${ }^{137} \mathrm{Cs}$, amounting to between 2 and $41 \mathrm{mCi} \mathrm{km}^{-2}$ (or between 74 and $1,500 \mathrm{MBq} \mathrm{km}{ }^{-2}$ ), suggest that the recent 